\title{
Clinical Study of Secondary Intraocular Lens Implantation
}

\author{
Dr. Kshitija Panditrao ${ }^{1}$, Dr. R. R. Naik ${ }^{2}$ \\ Department of Ophthalmology, PDVVPF's Medical College, Ahmednagar, 414111, Maharashtra, India
}

\begin{abstract}
Background: Secondary implantation of lens is an insertion of a lens in any eye rendered aphakic by trauma or previous surgery. Aims and objectives: To study and analyse the result of secondary IOL implantation. Materials and methods: This is a hospital based clinical study of 12 patients with aphakia attending the ophthalmology out patient department of our Hospital. These cases were treated surgically with secondary iol implantation and then results were analysed with respect to study of indications for secondary IOL implantation, the functional outcome following secondary IOL implantation and to understand the reason for poor visual acuity following secondary IOL implantation. Result: 12 patients underwent secondary IOL implantation. All were in the age group of 61 to 70. 83.33\% of patients had pseudophakia as the status of the other eye and $16.66 \%$ had aphakia in fellow eye. Monoocular aphakia with pseudophakia in fellow eye was the indication for secondary IOL implantation. $41 \%$ underwent ACIOL implantation, $41 \%$ underwent Scleral fixative and $16 \%$ underwent PCIOL implant in sulcus. $75 \%$ eyes had BCVA 6/12 or better and $25 \%$ had BCVA 6/24 or better. Striate keratopathy in $25 \%$, uveitis in $33.33 \%$ and Cystoid macular edema in $8.33 \%$. Interpretation and conclusion: Majority of patients seeking IOL implantation have monocular aphakia with good vision in the fellow eye. ACIOL and PCIOL have comparable results as per post operative visual acuity is concerned. Hence secondary IOL implantation is a good surgical option for patients with aphakia seeking to overcome their aphakic disability.
\end{abstract}

Keywords: Secondary IOL implantation, anterior chamber lens, Scleral fixation IOL, posterior chamber lens, glued IOLs

\section{Introduction}

Secondary implantation of lens is an insertion of a lens in any eye rendered aphakic by previous surgery ${ }^{1}$. Commonly used Intraocular lens (IOL) is anterior chamber lens, posterior chamber lens, scleral fixative IOLs or glued IOLs. Secondary implantation of lens is an insertion of a lens in any eye rendered aphakic by previous surgery. Commonly used Intraocular lens (IOL) is anterior chamber lens, posterior chamber lens, scleral fixative IOLs or glued IOLs. Disadvantages of aphakic spectacles including image enlargement, prismatic and peripheral aberrational effects leading to spectacle intolerance. Aphakic spectacles give a limited field of vision with a roving ring scotoma. Distance judgment is impaired with aphakic spectacles leading to clumsiness in performance of simple tasks. Contact lenses ameliorate many of these problems however there remains a magnification factor about $7 \%$ creating an aniseikonia for the unilateral aphakia. Contact lens wear is limited by factors like poor manual dexterity, old patients with arthritis etc

\section{Aims and Objectives}

- To study and analyze the result of secondary IOL implantation.

Though primary implantation forms the majority of intraocular lens implantation today, a large number of patients still seek remedy for their aphakic disability through secondary intraocular lens implantation.

\section{Material and methods}

This is a hospital based clinical study of 12 patients with aphakia attending the ophthalmology out patient department of our Hospital.

\section{Inclusion Criteria}

- Patient dissatisfied with visual rehabilitation obtained with aphakic spectacles.

- Patients with monocular uncorrectable aphakia.

- Patients with aphakia requiring binocular vision and unable to tolerate contact lenses.

- Patient has any condition that makes contact lens use difficult due to arthritis, hand tremors.

\section{Exclusion Criteria}

- Any severe condition such as proliferative diabetic retinopathy, uncontrolled glaucoma, retinal detachment, intraocular tumor, active inflammation of infection or recent ocular trauma.

- Presence of ocular defects -microphthalmos, aniridia, coloboma.

- Shallow AC, decrease in endothelial count to less than $1200 / \mathrm{mm}$ sq. which precludes use of ACIOL.

\section{Pre Operative Evaluation of the Patient:}

- Complete evaluation of the eye to be operated, along with evaluation of the fellow eye is also essential.

- Blepharitis, conjunctivitis, dacrocystitis should be excluded and if present should be treated prior to operation. Entropion, trichiasis and chronic infection of meibomian glands are looked for and treated.

- Pre-operative assessment of the operating eye in terms of best corrected visual acuity, sensitivity to light, pupillary reaction, B-scan ultrasonography is done.

- A detailed evaluation of the anterior segment including cornea, depth of anterior chamber, angle of anterior chamber.

- Posterior capsule intact or ruptured was noted. 


\section{International Journal of Science and Research (IJSR) \\ ISSN (Online): 2319-7064}

Index Copernicus Value (2013): 6.14 | Impact Factor (2015): 6.391

- Posterior segment evaluation using direct ophthalmoscope, indirect ophthalmoscope, 90D lens.

IOL calculation was done with SRK II formula. Keratometry was also done for any corneal astigmatism. All patients were operated by the same surgeon.

\section{Consent}

A well informed consent which includes risks and complications of the surgery and its anaesthesia. Patients were also explained about the complications like cystoid macular oedema or corneal decompensation.

\section{Post operative checkup:}

Patients were regularly followed up for a period of 3 months. Patients were followed up post op $1^{\text {st }}$ week $3^{\text {rd }}$ week $6^{\text {th }}$ week $2^{\text {nd }}$ month $3^{\text {rd }}$ month.

\section{Results}

A total of 12 eyes with aphakia were subjected to secondary intraocular lens implantation. Male female ratio 6: 6 showed that there was an equal number of males with aphakia seeking remedy for correction of their aphakic disability as the number of females.
Age Distribution of Patients

\begin{tabular}{|c|c|c|}
\hline \multicolumn{2}{|l|}{ Age } & Number \\
\hline \multicolumn{2}{|l|}{ 61-65 years } & 2 \\
\hline \multicolumn{2}{|l|}{$66-70$ years } & 7 \\
\hline \multicolumn{2}{|l|}{$>70$ years } & 3 \\
\hline \multicolumn{3}{|c|}{ Status of the other eye } \\
\hline Ocular condition & No. of eyes & Percentage \\
\hline Pseudophakia & 10 & $83.33 \%$ \\
\hline Aphakia & 2 & $16.33 \%$ \\
\hline Cataractous lens & 0 & 0 \\
\hline
\end{tabular}

Type of intraocular lens implantation

\begin{tabular}{|c|c|c|}
\hline & No. of eyes & Percentage \\
\hline PCIOL & 2 & $16.6 \%$ \\
\hline Glued IOL & 3 & $25 \%$ \\
\hline Scleral fixative IOL & 5 & $41.6 \%$ \\
\hline ACIOL & 2 & $16.6 \%$ \\
\hline
\end{tabular}

Best corrected visual acuity pre operative and post operative

\begin{tabular}{|c|c|c|c|c|}
\hline \multirow{2}{*}{$B C V A$} & \multicolumn{2}{|c|}{ Pre-operative } & \multicolumn{2}{c|}{ Post-operative } \\
\cline { 2 - 5 } & No. of eyes & $\%$ & No. of eyes & $\%$ \\
\hline 6-Jun & 0 & 0 & 2 & $16.66 \%$ \\
\hline 9-Jun & 0 & 0 & 3 & $25 \%$ \\
\hline 12-Jun & 2 & $16.66 \%$ & 4 & $33.33 \%$ \\
\hline 18-Jun & 3 & $25 \%$ & 0 & 0 \\
\hline 24-Jun & 1 & $8.33 \%$ & 2 & $16.66 \%$ \\
\hline Jun-36 & 2 & $16.66 \%$ & 0 & 0 \\
\hline 6/60 and less & 4 & $33.33 \%$ & 1 & $8.33 \%$ \\
\hline
\end{tabular}

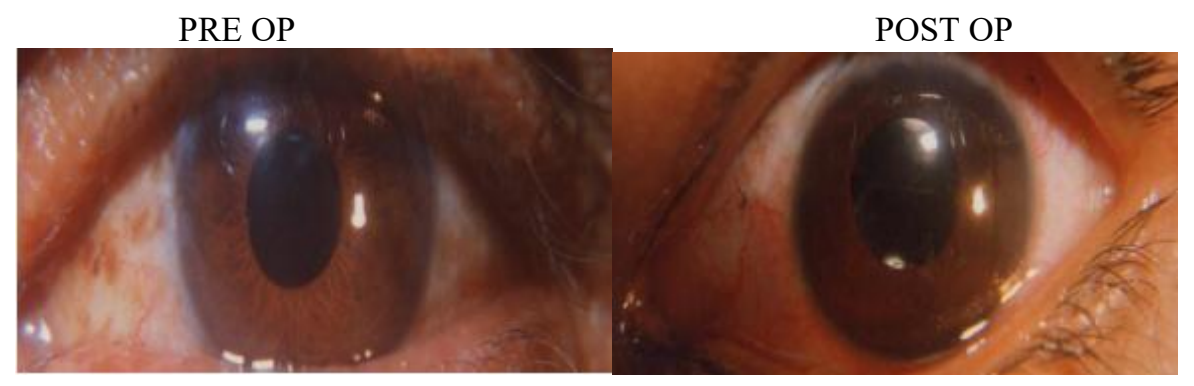

Scleral fixated IOL

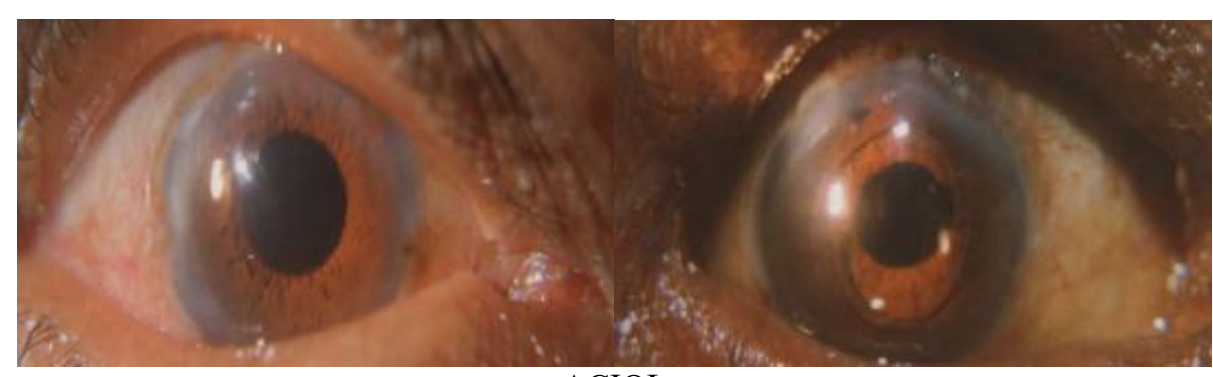

ACIOL

Early postoperative complication

\begin{tabular}{|c|c|c|}
\hline & Number & Percentage \\
\hline Striate keratopathy & 7 & $58.33 \%$ \\
\hline Uveitis & 2 & $16.66 \%$ \\
\hline Hemorrhage & 3 & $25 \%$ \\
\hline
\end{tabular}




\section{International Journal of Science and Research (IJSR) \\ ISSN (Online): 2319-7064}

Index Copernicus Value (2013): 6.14 | Impact Factor (2015): 6.391

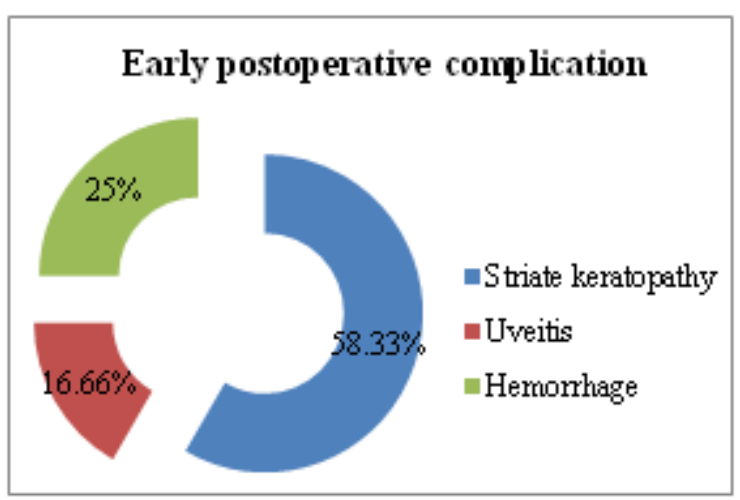

Late post-operative complications

\begin{tabular}{|c|c|c|}
\hline & Number & Percentage \\
\hline Corneal decompensation & 1 & $8.33 \%$ \\
\hline Cystoid Macular oedema(CME) & 1 & $8.33 \%$ \\
\hline Persistent uveitis & 2 & $16.66 \%$ \\
\hline
\end{tabular}

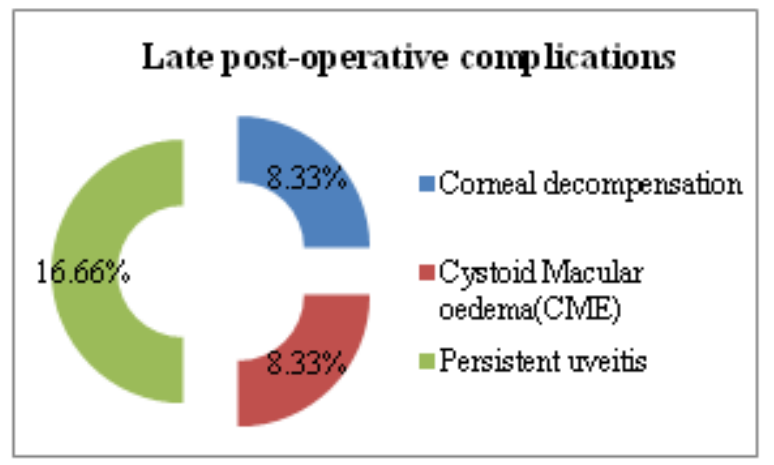

Corneal striae resolved within 2 weeks in 5 eyes. Out of the remaining 2 eyes one eye developed corneal decompensation. Uveitis was seen in 2 eyes. In 1 eye uveitis resolved within 3 weeks and 1 patient had to be given sub conjunctival injection of antibiotic steroid. One eye who had undergone ACIOL implantation developed persistent low grade uveitis when followed up for $3 / 2$ months.CME also resolved after giving Nepafenac eye drops.

Comparison of various complications occuring due to different IOL implantation

\begin{tabular}{|c|c|l|}
\hline Result of IOLs & No. of cases & \multicolumn{1}{c|}{ Complications } \\
\hline PCIOL & 2 & $\begin{array}{l}\text { Hemorrhage } \\
\text { Uveitis }\end{array}$ \\
\hline Scleral fixative & 5 & $\cdot$ Cystoid macular oedema \\
\hline Glued IOL & 3 & Hemorrhage \\
\hline ACIOL & 2 & $\begin{array}{l}\cdot \text { Hemorrhage } \\
\text { Uveitis } \\
\text { Corneal decompensation }\end{array}$ \\
\hline
\end{tabular}

\section{Discussion}

Azhar et $\mathrm{al}^{2}$ conducted a study regarding the complications during secondary IOL implantation and they concluded that haemorrhage in $13.9 \%$ and vitreous loss occurred in 3.9\% patients. Cystoid macular oedema occurred in $5.8 \%$ and corneal decompensation in $19.2 \%$ of patients.

In a series of 169 eyes implanted secondarily with ACIOLs Shammas $^{3}$ and Milke observed that $>65 \%$ of patient had an increase of visual acuity of one Snellen line. This correlates with our study wherein $>70 \%$ cases had improvement.
Significant complications do occur in a minority of patients undergoing secondary IOL implantation as comparable with other's study.

\section{Conclusion}

- Majority of patients seeking secondary intraocular lens implantation have monocular aphakia with good vision in the fellow eye.

- Comprehensive pre op. evaluation with respect to status of corneal endothelium. PC integrity, strands of vitreous in AC. biometry in aphakic mode to determine accurate IOL powers is essential to ensure successful visual rehabilitation following secondary IOL implantation

- Intra operatively delicate handling of tissues, adequate use of viscoelastics and constant maintenance of $\mathrm{AC}$ are pre requisites to minimize post op. complications.

- Regular post op. follow up recognition of complications and treatment of the same help in maintaining good vision post op.

- PCIOL implantation and scleral fixative IOLs have comparable results as per post op. complications were concerned.

- ACIOL has most severe and number of complications.

- Glued IOLs had the least complication rate. But this procedure is more expensive than the rest of the implantations.

- Hence secondary intraocular lens implantation is a good surgical option for patients with aphakia seeking to rid themselves of cumbersome aphakic spectacles or the difficult to use contact lenses to overcome their aphakic disability.

\section{References}

[1] L Dutta. C. Natchiar, Deva Prasad Kar Secondary Intraocular Lens Implantation" Chapter 59 m Modern Ophthalmology. Vol-L 3d Edition. L.cDutta. New Delhi. Jay Pee Brothers. Medical Publishers (P) Ltd. 2005, 434

[2] Azhar RF. Secondary implantation of intra ocular lenses. Ann. Ophthalmology 10: 658 - 662: 1978.

[3] Shammas. Milkie CF: Secondary implantation of anterior chamber lenses J. Ann Intraocular Implant Soca: $313-316.1983$. 